\title{
Strategic and Operational Planning: Impacting Results in International Business Study Programs
}

\author{
Kenneth Heischmidt \\ Southeast Missouri State University
}

Presented is a discussion of the macro and micro environmental issues to be considered when implementing international business study programs. A model is provided that diagrams the macro external environments displayed by the political, economic, social, technical, environmental and legal (PESTEL) influences in strategic planning, and the micro internal university structures/support and curriculum structures that impacts a schools offering of international study. A full discussion of the operational planning for short term and long term international business study is provided.

\section{INTRODUCTION}

Business schools across North America and throughout the world are impacted by AACSB accreditation standards that emphasize a need to internationalize the business curriculum and the school's student experiences (Gordon, Heischmidt and Greenwood, 2000). There are likely a number of goals related to international education, primary among these include a desire for students to develop a mutual understanding and respect for all members of the world community. There is the goal in most academic programs for all students to obtain value from experiencing others who are different from them through intercultural and international education.

Providing students international business experiences can be approached in a variety of ways. These ways include study abroad, bringing international speakers into the classroom, reading on international topics and case study analysis. An out of country study experience may be viewed as the most preferred approach for business students to learn about international commerce (Blasco, 2009). This paper will discuss a model of strategic and operational planning and associated results related to a successful development of outbound international study programs.

There are certain steps to apply environmental analysis. You first need to understand all of the relevant environments before moving on to the operational areas of planning for international study. You need to collect and understand all relevant related information. There is the need to both identify the opportunities and recognize the threats for your international study program. Finally, the thorough understanding of these environments leads to the clarification of your institution's strategic goals that flows in the creation of operational plans and measurements of results for these overall goals.

\section{MODEL OF STRATEGIC AND OPERATIONAL PLANNING}

While others have provided step by step model for developing a short-term study abroad program (Eckert,Luqmani, Newell, Quraeshi, \& Wagner, 2013; Schermerhorn, 2013; Bates \& Snell, 2013), this 
paper provides a strategic and operational model for understanding those factors that will impact the results of an international study program.

Planning for international study programs operates within two broad environments: macro and micro. The macro environments (Bates \& Snell, 2013) are the broad national and multinational environments impact plans while micro environments are those things closer to the decision maker, such as the state or institutional level. Broader macro strategic environments need to be first considered before operational environments within the university and people associated with the programs can be considered. Collectively these strategic and operational environments will impact the school's support and student participation results of these internationalization efforts. These strategic (macro) and operational (micro) areas are displayed in the following Model (Figure1).

\section{FIGURE 1 \\ STRATEGIC (MACRO) AND OPERATIONAL (MICRO) AREAS IMPACTING INTERNATIONAL STUDY}

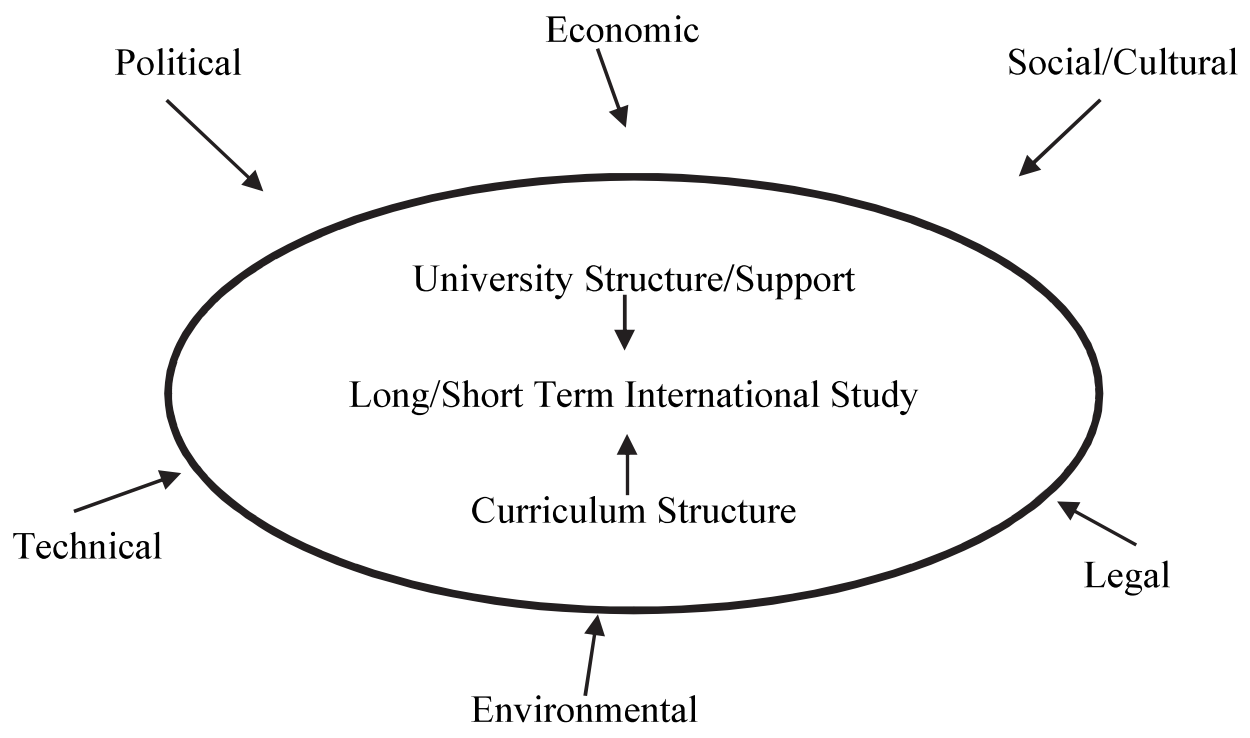

The model suggests that an effective approach to the planning of international business study programs starts first with a thorough review of strategic environments impacting this planning. Six macro environments will be discussed: political, economic, social/cultural, technical, environmental and legal (PESTEL) areas (Abbott, 2015: Marketing Theories: PESTEL Analysis, 2017; Solomon, Marshall \& Stuart, 2016). First, understanding the political environment.

\section{Political}

The importance of understanding the macro environments of decision making related to international education may very well start with understanding the political dynamics of the related decision making. Political changes both within and between countries may have a very large impact on how any international study program can be conceptualized and carried out. There are possible changes in national government leadership that may result in changing government policies that impact international travel. Recent examples of changes in domestic leadership in certain countries have resulted in both real and perceived changes related to issuance of entry visas for international travel to a country, modification of tariff agreements between countries, student safety and changes to guest worker programs. These changes and perceptions of stability may have resulted in changing attitudes of individuals living in other countries toward the home country. They may be less or maybe more willing to provide assistance with travel and company visits when compared to prior years. 
When a government changes political leadership, or retains current leadership, it provides the various audiences (both domestically and internationally) with the opportunity to view that government as being either stable or unstable. Any change may be viewed favorable or unfavorable depending upon the evaluator.

These political leadership changes generally center on being more or less inclusive to both domestic and international populations. These views are many times related to social/security and economic/trade considerations within the political environments. How do these changes impact international travel? Most relevant impact is on the interest by students and the encouragement and support of parents for their students to experience international travel. Concerns may certain around the feelings of safety in travel, agreement with domestic policies toward outsiders, and overall changes in views toward different nations. These concerns may impact individual students' willingness to participate in international study programs.

\section{Economic}

The economic forces look at the dynamics and direction of both national and world economies in which the institution operates. Institutions/Organizations desire to operate in a stable economic environment, yet witness an unstable economic environment consisting of some of the following problems: high inflation and interest rates, fluctuating currencies, trade and budget deficits or surpluses, fluctuating commodity, stock, and real estate markets, accessibility to credit, increasing unemployment, changes in disposable income within family households, changes in monetary and fiscal policies and budgets, and contracting gross domestic product (GDP).

The development of economic capability may result in more students from these countries being able to participate in international educational programs. For example, many students currently coming from China to study in the USA are financially able to participate in international study to a partner third country (ie. schools and programs in Europe) because of the increased financial capability of students from China. The next wave may be from students coming from India to study in the USA who then want to continue semester exchange programs with partners in Europe.

The contraction of an economic system within a country may result in a reluctance by students and their parents to venture out and try an international program. The economic capability of the sponsoring parent or student could be impacted by the overall state of the national and international economy. As the economy grows so does disposable income and thus possible international travel and study. The opposite also holds true.

\section{Social/Cultural}

The social and cultural areas of strategic environments to be considered by planners of international programs encompasses social lifestyle changes, educational levels, distribution of wealth within a society, the domestic structures, and demographic makeup within society. As a society changes so do opportunities for international education. Generally speaking, a more open society encourages international travel and education, in a closed society the opposite occurs. For example, participation rate of students in international study programs may vary significantly by gender depending upon the country students may come from. Student from more gender equal countries would likely have more equal participation in international study opportunities.

Education of the general population within a society tends to impact the interest for international education. Higher education levels tend to foster the increased interest levels for knowing what is available in the world, a center-piece of what international education provides to an individual.

Demographics may impact international educational interest. In a society that has a large number of small families, say one child, there tends to be more support for students to experience other cultures and educational opportunities. This may be a reflection of financial capability when a family only has one child and the desire to give this special student every opportunity available to them so they can be successful in life. 


\section{Technical}

The technical changes occurring in the world are providing an opportunity for international education that is quickly changing and difficult for many educators to keep up with in their institution. Related to this discussion, technical change refers to those changes related to creating and applying new knowledge to the process and results of education. Some of the broad areas of technical change include the growth of social media, collaborative learning, online learning, and data related assessment.

Social media changes the way students interact, process information, and arrive at conclusions. This worldwide growth of social media changes the way students and faculty interact with one another which has implications for communication and the exchange/processing.of knowledge. Students are no longer limited to learning only in the classroom or their campus library. Social media allows more of a community of learning with an informal exchange of ideas between students with other students and with their faculty. The faculty are becoming more facilitators of knowledge with an increased need to quick response to students who are interacting as a community of learners. Social media coupled with online learning provide opportunities undreamed of related to international education a couple of decades ago. There are opportunities for international education that brings together students from different countries for a more flexible and dynamic learning. This dynamic new learning environment may allow students to sample multiple international peer environments The sampled international environment may lead to an increased interest for actually visiting the countries and environments outside of their home country.

Another area of change provided by technology is in the promotion and planning of international education. While prior years may have required the use of travel professionals to facilitate international educational travel, new developed communication platforms allow almost any technically capable individual to plan and facilitate rewarding educational international travel experiences for students.

The educational environment is increasingly needing to provide an accountability for its educational efforts and expenditure of resources. Technology will allow educators to demonstrate a broadening of educational opportunities for students. Additionally, social media growth which is an outgrowth of technology change facilitates the continued relationship with students who have experienced international education and thus positively impacted their professional career paths.

\section{Environmental}

The environmental area of macro considerations with strategic planning in international education centers on the actual and potential future changes in the physical environment that may impact international education and how institutions will need to react to these physical changes. Areas to consider include climate change and global warming, energy consumption and national regulations in this area, waste disposal laws, pollution, and the overall attitudes of various individuals within nations toward the environment.

The impact that pollution has on global warming provides a rich area for facilitation of education. There is the opportunity for students from around the world to learn from international travel how various leading forward acting nations actually are addressing pollution concerns. Observing how the creation of efficient national public transportation systems or the relationship of taxes on petroleum and more efficient private vehicle transportation, can reduce pollution within a country may be very eye opening for many students. Seeing firsthand how nations deal with waste disposal and recycling may be a turning point in some student's life.

\section{Legal}

The legal dimension of macro environments influencing international education centers on laws and regulations at the state, national and international level. These laws and regulations include taxation, regulations/deregulations, legal travel and documentation, labor laws and employment, liability and safety, and contracts.

The legal dimension centers on the legal requirements of possible travel. Are passports and visas required of certain students from other countries? Is travel to certain countries even allowed? Dealing with students coming from many countries may require a close review of the legal, health, and financial 
documentations required of students visiting international locations. In addition, any hosting institution needs to fully understand the legal reporting requirements at the national level for incoming students.

Related to facilitation of international travel, administrators need to fully understand the state and national rules and laws related to buying, contracting, and making payments for travel. Additionally, there is a need for an awareness of how academic credit is measured and is transferred between countries and institutions.

An international-focused academic program and student body helps ensure the students attending an institution are exposed to and experience international perspectives and develop a global competence and skill base in order to succeed in their future life efforts. International experiences prepare students to succeed in an ever increasing global environment with changing political and economic landscape. Upon the thorough review and consideration of the macro environments impacting international education an institution needs to consider the micro environments of international education. The active participation/experience is the most obvious implementation in international education. The development of international study programs is complex and involved. Planning international study programs involves many areas of consideration and development (Heischmidt \& Gordon, 2014). The following discussion will share information related to the micro issues related to implementing an international experience for students.

\section{OPERATIONAL PLANNING FOR UNIVERSITY}

Study abroad has been very popular in Europe for a number of years (Peitro and Page, 2008). Universities have developed opportunities for their students to study for a semester or entire school year at a school outside of their home country. An abbreviated opportunity is a shorter term immersion program of 2-3 weeks for students to travel internationally to visit and experience businesses and cultural sites (Heischmidt and Gordon, 2010).

\section{University Support/Structure}

International study opportunities need full support of the administrative personnel at their university, including department chairs, college deans, provosts, and the university president. Without their active support international programs have a reduced chance of success. The support includes administrative leverage in terms of finances (for students and faculty), procedures and structures. One example, the creation of selected scholarships to assist both student and faculty international programs can provide a significant boost to any international effort. The recognition of internationalization efforts by faculty in the tenure and promotion process will send a signal to faculty of the worth of their time and effort participating in the international efforts.

The structure of the university can facilitate the development of international study programs and impact the larger administrative issues of international study. For example, is there an international support center at the university campus to assist with international efforts at all levels? If so, what is the focus of the international center related to the role of a broader educational purpose of the university? Is it recruiting of incoming international students or the facilitation of international outgoing programs? If the focus is on incoming students, assistants will likely be directed toward incoming students with less effort allocated to outgoing students. A focus on outgoing programs may facilitate the development of both semester long and short term outgoing international study programs for students by the university. This facilitation could be helpful to students considering international study as well as the willingness by faculty to development and promote such programs. Another example would be the policy of the university registrar related to accepting the transfer of credit. What amount of credit does a five hour ECTS (European Credit Transfer System) course transfer into the home institutions credit acceptance policy? Does it come in as three or two semester hour course with the domestic institution? There are also concerns that need to be addressed related to differences in international grade scales (eg. 4 or 10 point grading scales used by international institutions) and the normal distribution of grades in a class (a bell curve or positively skewed curve). 


\section{Curriculum Structure}

Students understand an international experience as an enhancement to their education and want the experience to count toward their degree. Faculty organizing international experiences for students need to understand this aspect of academic credit into their planning. Faculty need to review if there are areas related to students' degree programs that accept for credit the classes a student may take internationally? Is there academic flexibility at the university (common university studies), college and department levels to accept either course credit or course substitution from both international transfer credits when a student completes an international program delivered by the institution? Students and parents both desire these international experiences to apply toward graduation and this becomes part of their overall evaluation of the international experience decision. If a student and parent are paying for an experience it needs to contribute to the students' academic degree structure in some constructive way.

\section{OPERATIONAL PLANNING FOR LONG TERM VS SHORT TERM INTERNATIONAL STUDY}

A long term international study experience may be defined as lasting more than eight weeks abroad, typically a semester or a year. Short term international opportunities are usually less than eight weeks. A long term experience is appropriate for students who have the financial resources, home and work flexibility, and are able to structure the experience to avoid delay in graduation (Kehl and Morris, 2007).

Semester long international business study programs fall under three different models: direct enrollment, hybrid programs, and island programs (Hanouille and Leuner, 2001). Direct enrollment places students directly into courses at the receiving international institution. Hybrid programs have students take a combination of classes at the hosting institution as well as taking classes from a faculty member at their home institution. Island programs are self-contained programs that have faculty of the home institution providing all instruction to the participating students, yet everyone is located together overseas, usually at a host institution (Hanouille and Leuner, 2001).

These semester long international study programs may not suit all students (Ladika, 2009). Some students do find it difficult to be away from their home institution for an extended period of time. Many students, including first generation college students as well as nontraditional students, fall within the situations mentioned above (Shallenberger, 2009). These students who wish to be exposed to international business experiences, and may need to have options in addition to the traditional semester long exchange program (Gordon, and Heischmidt, 2000).

\section{LONG TERM PROGRAMS}

Long term programs provide students with opportunities to study outside of their home country for one or two semesters. Timing of a semester long program is important. Many universities outside of the U.S. have academic calendars that are different from the U.S. calendars. For example, southern hemisphere schools have summer break when schools in the northern hemisphere are in the middle of winter and have active academic events. Additionally, the start of semesters might be significantly different within northern hemisphere schools. In Germany, for instance, the "fall" (winter) semester begins in October and ends in late February. "Spring" (summer) semester begins in March and finishes in late June/July.

Students will be evaluating an international program and applying this experience to their degree requirements. A semester long experience will likely have a student completing a semester worth of classes at the host institution that hopefully lead to the credits being transferred back to the students home institution. Care needs to be taken to confirm that all courses completed by the students while on the international program count toward degree requirements. 


\section{Types of Long Term Study Possibilities}

Once timing issues related to the academic calendar are evaluated, the review of long-term possibilities and agreement need to be considered. The long-term agreements fall into multiple categories: bi-lateral agreements, consortium agreements, overseas campuses, and direct application.

Bi-Lateral Agreements consists of partnering home institution with an international partner for a one to cone agreement. There is generally an agreement related to reciprocal tuition, lodging assistance, and an international office at both partnering schools that provides guidance and assistance to participating students from both the providing and hosting institution.

Consortium Agreements center on nonprofit organizations that specializes in facilitating student exchanges among a number of partnering institutions. The student exchange program is facilitated by this nonprofit organization between schools that are location in different countries and on different continents. The institutions in the consortium pay an annual membership fee in return for the necessary administrative that facilities successful student and faculty exchanges.

Another type of semester long opportunities is provided by university owned campuses in an Overseas Campuses by some larger universities. These satellite campuses provide a modified range of student services and education as offered at the home institution. These overseas locations require an upfront financial commitment from the home school.

An understanding that some universities in selected countries do not charge tuition to foreign students may allow a student to have Direct Application to such international universities for a semester. This approach requires that a student initiates and carries out all aspects of an exchange with the assistance of a home institution. While this possibility is available for a prospective student, they would be faced with the task of gaining admission to international university, individual coping with the housing and assimilation process as well as the need to transfer grades back to the home university.

\section{SHORT TERM PROGRAMS}

In contrast to semester long programs of international study, a study program that consists of a shorter period of time may be appropriate for many university students, usually consisting of one to three weeks. An appropriately designed short term program may allow many students, including a growing number of nontraditional students, a chance to personally experience international business even though they need to balance family and jobs at home. The contributing factors that make short term international study programs appropriate for many students include price and location, programs promotion, curriculum issues, travel arrangements, and academic delivery.

The Price and Location of a program are very important to a prospective student. Students are more likely to select and participate in programs that are both reasonably priced and are offered to attractive locations. Items that go into the price portion of the equation include: are grants or scholarships available to support international travel by students, does the institution pay for the expenses of the accompanying faculty members, and is the location selected an excessively expensive location to visit? Organizing faculty need to decide if they want one international location with possible day trips out of that location or a multi country/ multi-city experience. Both ways have their advantages. A single location allow for more in depth immersion into one international culture and cuts down on pre-trip arrangements, hotel check-in and check-out responsibilities. One location reduces between country travel costs and travel visa requirement for certain students. Students become familiar with their surroundings and gain independence with the one culture visited. There also needs to be a consideration of when is the best time for students to get one, two or three weeks of time away from their responsibilities of work or family. The scheduled academic breaks between semesters, during January and spring break periods, appear to be natural periods to arrange one to two week short term programs, while end of spring/beginning of summer semester in May and June is best for programs of three weeks or longer. 


\section{Program Promotion}

Faculty members then need to promote the international study in order to communicate the international study opportunity to students by way of posters, emails to prospects, program information sessions to student groups, and presentations in classes (Heischmidt, Gordon, and Dobson, 2000). Soliciting excitement for the program by many of the faculty throughout the college provides a favorable environment for building student interest for the programs. The faculty need to dedicate time to personally talk with almost every student that considers these study opportunities, some of whom with decide to apply for the program and a number will decide not to apply.

Faculty need to get the student excited about international travel. Recruiting of students is a reflection of the support of the institution and advocacy by interested faculty; it is a process that needs to be continued throughout the entire school year (including summer). For programs that have been previously offered and have a history of success a favorable word-of-mouth will help attract future students' applications for these international programs.

\section{Curriculum}

For students on short term programs, decisions need to be made as to the credit the student is to receive, will it be two, three, four hours? These credits for students need to apply in general studies credit, their major, or their minor. Credit is related to the intent of the program. Is the program cultural in nature or business related international experiences? Cultural programs may be best suited for general studies credit; while programs with focus on business visits are appropriate for business credit.

\section{Travel Arrangements}

While an on campus international center that assists with travel aspects of international programs is very helpful, if this travel assistance is not available on campus, the faculty member has the choice to make arrangement on their own or use an outside travel broker. The advantage of a travel broker is the significant time savings for the faculty member. The major disadvantage is the extra financial costs associated with a broker. Some companies have pre-established travel dates for groups and they may consolidate your group with another group if the number of students falls short of a full coach (usually about forty or more students). This consolidation may involve your university group being combined with a group of another age, such as high school students or senior citizens.

If a travel broker or travel agent is not used, then the faculty member will need to make all travel arrangements. These arrangements include the following: air travel, reservations at hotels in all the cities visited, travel to and from departing and arriving airports, travel between hotels, travel within cities, travel to business that may be on the schedule, museum passes and tickets, guest speakers and location for these speakers, all meals that are included, and all other scheduled events for the group. The primary advantage of the faculty organizing travel and other needs is the assurance that arrangements are done correctly and the costs are usually lower because you are not paying broker fees. The disadvantage is the time expense for the faculty member to make all of these arrangements.

\section{Academic Delivery}

Once the international program is organized and students enrolled, the offering of pre-departure classroom sessions is appropriate. Students attend sessions prior to departure that allow them to know one another as well as the faculty members accompanying them on the program overseas. In these sessions, daily operational issues related to international travel are covered. There will be experiences significantly different (behavior, governments, foods, people, words, languages, etiquette, customs, airline travel, weather, foreign language, etc.) than the student is accustomed to at their home institution. In addition to the classroom information, a website should be established for students to visit to become familiar with the countries, cities and businesses they may visit.

An itinerary needs to be provided in a student orientation as well as appropriate academic expectations of students. There should be multiple pre departure assignments that allow a student to become familiar with the countries, cultures, business conditions, and companies they will visit. Student 
work pre-departure will enhance their international experience, especially for traveler on their first program outside of the country. During the overseas visit and upon return home, the students should maintain a daily diary of their travel observations and a reflective written narrative of comparisons between home cultural, economic, social environments and the corresponding environments of the countries visited. Developing a structured cultural comparison assignment for the students to follow during their program will assist them in their reflection upon return to their home country.

\section{OPERATIONAL PLANNING FOR PEOPLE}

\section{Student Background}

The prospective students' backgrounds need to be considered when designing international study programs. These considerations include their age and maturity, past travel experience, financial capability, and academic background. Different universities attract a student body that varies related to academic ability, financial resources, life experiences (which may impact maturity), parental support and expectations of the university experience. Students enrolled in large urban universities tend to be different from students attending smaller rural academic communities. Students attending private institutions may have more robust financial assets than students attending small regionally oriented state schools. Understanding these factors may go a long way in the decisions related to designing successful international study programs, such as costs incurred; minimum academic level required; prerequisite course; or academic credit hours earned prior to travel.

\section{Faculty Background}

It is important to understand the background and personality of the facilitating faculty involved with planning, recruiting, coordinating and traveling with the students on an international program (Carver and Byrd, 2008). Faculty coordinators need to be able to relate to students and to get them excited about a program of international study. Faculty members should have prior travel experience with the areas to which they will be sending/leading students and there needs to be a least two faculty accompanying any group traveling internationally. A whole host of unexpected events may arise that require multiple faculty leaders. Issues related to sickness of students and even a faculty member, delayed students, lost passports, split up groups on the airline travel, and student discipline.

\section{Students Background and Focus}

As mentioned in the considerations section, the background of students needs to be considered when designing both full semester and short-term international study programs. The prospective students' background considerations include their age and maturity, past travel experience, financial capability, and academic background. Short term programs might be an attractive alternative to semester long programs, for students with limited travel experience, limited financial resources, and those who are younger, less mature with a fear of the broader world.

Especially for upper level students, short term programs need to be academically focused. For example, this may mean short term programs designed specifically for business students. Incorporating the usual visits to cultural and historic sites with visits to businesses and presentations by business leaders will provide the richest learning experience. The use of alumni and the international affiliates of local businesses greatly facilitate the arrangement of speakers and plant tours at their affiliates in international locations. Many times, the international affiliate is excited to host faculty and students from the "sister facility/city".

\section{Costs}

One advantage of short term programs is the cost, which is usually less than semester long programs. The financial capability of prospective students will impact the actual budget of the program. In order to keep the cost of a program as low as possible so as to appeal to the broadest possible range of students, institutional/faculty planned programs can be arranged for student international experience, but 
necessitate faculty members planning that is far greater than pre-packages programs. Included in these planning items are travel, sightseeing, dining and lodging arrangements. Pre-packaged programs from commercial providers, such as Education First (EF) Tours and Casterbridge Tours, provide excellent educational tour programs, but at a cost which is usually higher than that of institutionally arranged programs. Again, developers of international programs need to look at their institution and both the demographics and social/economic makeup of the student body attending the institution.

\section{Faculty Background}

The faculty members involved with a school planned international travel program must first consider the level of personal involvement they will need to invest in organizing the experience. Organizing faculty members need to check on travel policies of their university. Some schools have pre-established policies and procedures for such travel. Policies related to bidding, contracting and payments on travel arrangements must be clarified. Additionally, the faculty must be familiar with the policies for reimbursement of travel expenses incurred by the faculty in possible program planning as well as actually traveling with students.

Next, the faculty organizer should then investigate if their school has an in house travel office to assist or maybe even complete this entire step for the faculty. The main role of the faculty member in such a case is to establish an effective communication channel with the travel office to assure the intended travel plans are in agreement between both parties and to follow up on a regular time frame to assure the arrangements for the travel are completed.

\section{RESULTS FOR UNIVERSITY AND STUDENTS}

\section{Overseas opportunities for faculty}

While the above discussion has focused on the needs of the students in higher education, another consideration is the potential for faculty internationalization associated with participating in international exchanges. Perhaps multiple faculty members want to participate in international study programs so they can bring international experiences back to their classroom. The semester long or short term international study program allows the facilitating faculty to bring an international experience to many more students at their home institution who otherwise miss out on this internationalization of the classroom.

There are benefits to students for international study programs Short term programs have provided very positive benefits for student participants (Carley, Stuart and Dailey, 2011; Ritz, 2011). An increase in personal maturity and a broader world perspective are among these benefits. Eckert, Luqmani, Newell, Quraeshi, and Wagner (2013) provide a summary of benefits to students who study abroad. Dwyer and Peters (2013) documented the value of long-term impact of study abroad. Their findings show study abroad positively influences the career path, worldview, and self-confidence of students (Dwyer and Peters, 2013). Chieffo and Griffiths (2004) documented the educational impacts of international short term programs on students' educational endeavors and personal lives.

The basic decision for globalization at an institution may include bringing in more international students (either degree seeking or exchange students) into the university. The development of the local domestic student body may be accomplished by exposure of international cultures on campus, curriculum development, short term international study programs, semester long study program, and dual degree programs with international partner institutions. How globalization is accomplished is dependent upon the macro and micro environments that impact an institution. 


\section{BIBLIOGRAPHY}

Abbott, R. J. (2015). Pestel Analysis for Students, (2nd ed). Create Space Independent Publishing Platform.

Bates, T. S., \& Snell, S. A. (2013). Management: Leading and Collaborating in a Competitive World (10th ed.). New York, NY: McGraw-Hill Irwin.

Blasco, M. (2009). Cultural Pragmatists? Student Perspectives on Learning Culture at a Business School. Academy of Management Learning \& Education. Briarcliff Manor: 8 (2), 174-187.

Carley, S., Stuart, R. \& Dailey, M. (2011). Short-Term Study Abroad: An Exploratory View of Business Student Outcomes. Journal of Management Policy and Practice, 12 (2), 44-53.

Carver, P.P. \& Byrd, J.T. (2008). Marketing a European Experience to the Less Traveled. Journal of American Academy of Business, Cambridge. Hollywood. Sept. 14 (1), 131-136.

Chieffo, L., \& Griffiths, L. (2004). Large-Scale Assessment of Student Attitudes after a Short-Term Study Abroad Program. Frontiers: The Interdisciplinary Journal of Study Abroad, 10 (fall), 165177.

Dwyer, M. \& Peters, C. (2013). The Benefits of Study Abroad. Retrieved April 1, 2013, from http://www/transotopmsabrpad/cp,/publications/magazines/0403/benefits_study_abroad.shtml, April

Eckert, J., Luqmani, M., Newell, S., Quraeshi, Z., \& Wagner, B. (2013). Developing Short-Term Study Abroad Programs: Achieving Successful International Student Exchanges. American Journal of Business Education, 6 (4), 439-458.

Gordon, P. \& Heischmidt, K.A. (2000). Segmenting the Market to Maximize Curriculum Globalization. Allied Academics, Inc. Proceedings of the Academy of Marketing Studies, October, 5 (2), 11-12.

Gordon, P, Heischmidt, K, \& Greenwood, R. (2000). How to Internationalize the Business Curriculum: Some Ideas That work Based on Experience. Proceedings of the Western Decision Science Institute, Fall, 308-310.

Heischmidt, K.\& Gordon, P. (2010). International Business Study Programs in a Challenging Economy. North American Management Society Conference Proceedings 2010, March 24, 95-101.

Heischmidt, K. A. \& Gordon, P (2014). International Business Study Programs: Outgoing Approaches. Journal of Higher Education Theory and Practice. 14 (1), 60-68.

Heischmidt, K., Gordon, P., \& Dobson, J (2000). How to Increase Student Participation in International Programs: A Discussion of a Program That Works. North American Management Association Proceeding, Spring, 14-16.

Hanouille, L.\& Leuner, P. (2001). Island Programs: Myths and Realities in International Education. World Education News \& Reviews. 14 (1), 1-6.

Kehl, K. \& Morris, J. (2007-2008). Differences in Global-Mindedness between Short-Term and Semester-Long Abroad Participants at Selected Private Universities. Frontiers: The Interdisciplinary Journal of Study Abroad. 15 (Fall/Winter), 67-79.

Ladika, S. (2009). Beyond Stereotypes in Education Abroad. International Educator, Washington. 18 (2), 28.

Marketing Theories - Pestel Analysis (2017, September 28). Retrieved from http://www.professionalacademy.com/blogs-and-advice/marketing-theories---pestel-analysis

Pietro, G. \& Page, L. (2008). Who Studies Abroad? Evidence from France and Italy. European Journal of Education. 43 (3), 389-398.

Ritz, A. (2011). The Educational Value of Short-Term Study Abroad Programs as Course Components. Journal of Teaching in Travel \& Tourism. 11(2), 164-178.

Schermerhorn, J. R. (2013). Management (12th ed.). Hoboken, NJ: Wiley.

Shallenberger, D. (2009). Education Abroad for Adult Students. International Educator, Washington. $18(1), 50$

Solomon, M.R.; Marshall, G.W. \& Stuart, E.W. (2016). Marketing: Real People, Real Choices (8th ed.). Boston: Pearson.

102 Journal of Higher Education Theory and Practice Vol. 18(1) 2018 